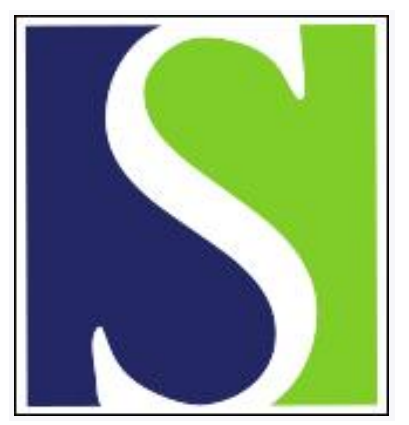

Scand J Work Environ Health 2002;28(1):12-17

https://doi.org/10.5271/sjweh.641

Issue date: Feb 2002

Risk factors for cardiovascular malformation - a study based on prospectively collected data

by Cedergren MI, Selbing AJ, Källén BAJ

Affiliation: Department of Obstetrics and Gynaecology, University Hospital, SE-581 85 Linköping, Sweden. marie.cedegren@lio.se

Key terms: body mass index; cardiac defect; cardiovascular malformation; drugs; parental age; prospective data; prospectively collected data; risk factor

This article in PubMed: www.ncbi.nlm.nih.gov/pubmed/11873776

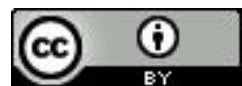




\title{
Risk factors for cardiovascular malformation — a study based on prospectively collected data
}

\author{
by Marie I Cedergren, MD, ${ }^{1}$ Anders J Selbing, PhD, ${ }^{1}$ Bengt AJ Källén, PhD ${ }^{2}$
}

\begin{abstract}
Cedergren MI, Selbing AJ, Källén BAJ. Risk factors for cardiovascular malformation - a study based on prospectively collected data. Scand J Work Environ Health 2002;28(1):12-17.

Objectives The aim of this study was to identify risk factors for cardiovascular malformation.

Methods In a case-referent study prospectively collected data were obtained from original medical records. The study included 277 woman who had infants with a severe cardiac defect, and for each case two referents (medical records study) were included. Data on parental age, maternal reproductive history, disease in early pregnancy, reported maternal use of drugs and alcohol, smoking habits, parental occupation, and maternal body mass index (BMI) were extracted. When data were available from Swedish medical health registers, a comparison was made (register study) between all infants with cardiovascular defects (2208) and all infants born (175 768).

Results Maternal diabetes mellitus was associated with an increased risk for cardiovascular malformation [odds ratio (OR) 2.38, 95\% confidence interval $(95 \% \mathrm{CI}) 1.36-4.15]$, as was a high $\mathrm{BMI}(>29)$ (OR 1.46, 95\% CI 1.12-1.90). A tendency towards an increased risk was found for involuntary childlessness, spontaneous abortion, thyroid drugs, and nonsteroid anti-inflammatory drugs.

Conclusions Some known risk factors for cardiac defects (eg, maternal diabetes mellitus and the use of antiepileptics) could be identified. Other postulated risk factors could not be verified, for example, paternal age and parental occupation. The use of medicinal drugs seems not to be a major factor in the etiology of cardiac defects. It is possible, however, that there is an association with the use of nonsteroid anti-inflammatory drugs or drugs for thyroid disease. The relationship between a high BMI and cardiovascular malformation observed in this study may be explained by impaired maternal glucose tolerance.
\end{abstract}

Key terms body mass index, cardiac defect, drugs, parental age, prospective study.

Cardiovascular malformation is one of the most common birth defects. The rate of cardiovascular defects depends on the definition, follow-up time, and inclusion criteria. Rates of 5-8 per 1000 live births have been given, and still higher rates have been reported for stillbirths (1). The etiology is thought to be multifactorial with both genetic and nongenetic factors interacting. Many studies have been published on possible associations between various maternal exposures and congenital heart defects.

Using a retrospective case-referent model, the large Baltimore-Washington study $(\mathrm{N}=3377)$ investigated several risk factors for cardiac defects in general and also specific cardiac defects (2). Family history of cardiovascular malformation, diabetes mellitus, maternal age of more than 34 years, previous spontaneous abortion, smoking, and alcohol use in early pregnancy were significantly associated with congenital heart defects.

A Finnish study (3) $(\mathrm{N}=408)$ based on retrospective data obtained from interviews found that maternal alcohol consumption, maternal exposure to dyes, lacquer and paint, and maternal upper respiratory infections were significant risk factors for cardiovascular malformation.

Studies based on data from Swedish medical health registers $(4,5)$ could not verify maternal age as a risk factor, whereas maternal smoking was weakly but significantly associated with congenital heart defects.

The aim of the present study was to identify putative risk factors for congenital heart defects in a

1 Division of Obstetrics and Gynaecology, Department of Health and Environment, Faculty of Health Sciences, Linköping University, Linköping, Sweden.

2 Tornblad Institute, University of Lund, Lund, Sweden.

Reprint requests to: Dr Marie Cedergren, Department of Obstetrics and Gynaecology, University Hospital, SE-581 85 Linköping, Sweden. [E-mail: marie.cedergren@ lio.se] 
register study and a medical records study. The register study was based on the total number of births, and exposure information was extracted from the Medical Birth Register. To supplement and enhance the quality of exposure data, we selected infants with a severe cardiac defect and the referents were matched. In the casereferent study design, original medical records of both the cases and referents were the source of exposure information. This latter approach could only be used for a subset of factors and was therefore restricted to infants with a relatively severe cardiac defect. In both the register study and the medical records study, exposure information was collected prior to knowledge of the outcome, recall bias thus being avoided.

\section{Materials and methods}

The study was made in the southeast region of Sweden, and therefore it was possible to retrieve the original records of the majority of the patients. The study period was 1982-1996.

\section{Register study}

During this period 175768 infants were born of women who lived in the region at the time of delivery. In a previous paper (6), we described the identification of infants with congenital malformation from various medical health registers. Infants with a known chromosome anomaly were excluded from the present study. The total number of infants with a cardiovascular malformation, excluding persistent ductus arteriosus (PDA) and single umbilical artery (SUA), was 2208, that is, 13 per 1000 births. The distribution of cardiac diagnoses is shown in table 1.

\section{Medical records study}

Of the infants with a cardiovascular malformation, 277 (1.6/1000 births) were identified from the Child Cardiology Register, which is based on specific reporting of all children with a cardiac defect referred before the age of 1 year to one of the child cardiology centers in Sweden (7). The diagnostic quality is high, and this subsample represents relatively severe cardiac defects (about $10 \%$ of all cardiovascular malformations), which were used as cases in a case-referent study. For each case, two referents were selected from the Medical Birth Register (8) from among infants born in the region the same year as the case and with maternal age as close as possible to that of the case. Matching for maternal age was made in order to avoid confounding of maternal age - maternal age as a risk for cardiac defect was studied using register data.

Data were collected from medical records without blinding as to whether the infant represented a case or a referent. Records for 8 cases and 30 referents could not be found. Medical records have a standard format throughout Sweden. From these, data on maternal and paternal age, period of involuntary childlessness, number of spontaneous and induced abortions, number of previous intrauterine deaths, maternal diseases in early pregnancy, reported maternal use of drugs, smoking habits, stated use of alcohol, and maternal and paternal occupation were extracted. Maternal weight and height were recorded when present and the body mass index (BMI) was calculated. All information was recorded at the mother's first visit to the antenatal care center (usually week 10-12 of pregnancy) and was thus prospectively related to the identification of the cardiac defect. Maternal and paternal occupations were coded using the Nordic Classification of Occupations. Drugs were coded using the ATC (anatomic, therapeutic and chemical) system.

\section{Statistical analyses}

In the register study odds ratios (OR) were determined using the Mantel-Haenszel technique (9) after suitable stratification. Estimates of $95 \%$ confidence intervals (95\% CI) were made with a test-based method (10).

The exposure proportions among the cases and referents in the medical records study were compared with Fisher's exact test. Matching was thus broken. Odds ratios and exact $95 \%$ confidence intervals were determined with Fisher's exact test using SABER software (Centers for Disease Control and Prevention, Atlanta, GA 30333, USA). A linear logistic regression analysis, adding maternal age as a confounder, was tried but it did not affect the odds ratios.

Table 1. Distribution of cardiac defect diagnoses in the register study (total number of infants $=2208$ ). Each infant could have more than one cardiac diagnosis.

\begin{tabular}{lr}
\hline Cardiac defect & N \\
\hline Atrial septum defect & 157 \\
Ventricular septum defect & 667 \\
Endocardial cushion defect & 29 \\
Single ventricle & 32 \\
Tetralogy of Fallot & 55 \\
Common truncus & 15 \\
Transposition of great vessels & 65 \\
Hypoplastic left heart syndrome & 33 \\
Pulmonary valve malformations & 70 \\
Coarctation of aorta & 95 \\
Other and unspecified defects & 1306 \\
\hline
\end{tabular}


Table 2. Effects of maternal and paternal age on the risk of cardiac defect in the infant. The odds ratios (OR) for congenital heart defect in the offspring in relation to maternal age were calculated from the data for cases and for all infants born in the region (the referents in the medical records study were matched for maternal age). Stratification was made for year of birth and parity. The odds ratios for congenital heart defect in the offspring in relation to paternal age were calculated from a case-referent comparison in the medical records study. (95\% Cl = 95\% confidence interval)

\begin{tabular}{|c|c|c|c|c|c|c|c|}
\hline \multirow[t]{2}{*}{ Age group } & \multicolumn{3}{|c|}{ Maternal age } & \multicolumn{4}{|c|}{ Paternal age } \\
\hline & $\begin{array}{c}\text { Cases } \\
(\mathrm{N})\end{array}$ & $\mathrm{OR}$ & $95 \% \mathrm{Cl}$ & $\begin{array}{l}\text { Cases } \\
(\mathrm{N})\end{array}$ & $\begin{array}{l}\text { Referents } \\
\text { (N) }\end{array}$ & $\mathrm{OR}$ & $95 \% \mathrm{Cl}$ \\
\hline$\leq 19$ & 11 & 1.43 & $0.78-2.62$ & 1 & 3 & 0.67 & $0.07-6.50$ \\
\hline $20-24$ & 67 & 1.11 & $0.82-1.49$ & 22 & 41 & 1.13 & $0.67-1.90$ \\
\hline $25-29$ & 93 & 0.86 & $0.67-1.11$ & 73 & 116 & 1.31 & $0.98-1.76$ \\
\hline $30-34$ & 69 & 1.05 & $0.80-1.40$ & 41 & 124 & 0.68 & $0.48-0.97$ \\
\hline $35-39$ & 21 & 0.81 & $0.51-1.27$ & 27 & 62 & 0.90 & $0.57-1.41$ \\
\hline $40-44$ & 8 & 1.90 & $0.93-3.87$ & 14 & 17 & 1.03 & $0.35-3.02$ \\
\hline$\geq 45$ & - & . & . & 5 & 13 & . & . \\
\hline Unknown & - & . & . & 86 & 148 & . & . \\
\hline Total & 269 & . & . & 269 & 524 & . & . \\
\hline
\end{tabular}

Table 3. Maternal reproductive history in relation to the risk of having an infant with a congenital heart defect.

\begin{tabular}{lccrc}
\hline Reproductive history & $\begin{array}{c}\text { Cases } \\
\text { (N) }\end{array}$ & $\begin{array}{c}\text { Referents } \\
(\mathrm{N})\end{array}$ & OR & $95 \% \mathrm{Cl}$ \\
\hline Years of involuntary childlessness & & & \\
$\quad$ None stated & 245 & 488 & 1.0 & Reference \\
$1-2$ years & 12 & 19 & 1.26 & $0.55-2.78$ \\
$\geq 3$ years & 12 & 17 & 1.41 & $0.60-3.18$ \\
Any & 24 & 36 & 1.33 & $0.74-2.35$ \\
Spontaneous abortions & & & & \\
0 & 204 & 416 & 1.0 & Reference \\
1 & 49 & 79 & 1.26 & $0.83-1.91$ \\
2 & 12 & 21 & 1.17 & $0.51-2.54$ \\
$\geq 3$ & 4 & 8 & 1.02 & $0.22-3.86$ \\
Any & 65 & 108 & 1.23 & $0.85-1.76$ \\
Induced abortion & & & & \\
0 & 224 & 445 & 1.0 & Reference \\
1 & 39 & 68 & 1.14 & $0.72-1.77$ \\
2 & 6 & 11 & 1.08 & $0.32-3.25$ \\
Any & 45 & 79 & 1.13 & $0.74-1.71$ \\
Parity & & & & \\
1 & 96 & 217 & 0.79 & $0.57-1.08$ \\
2 & 91 & 171 & 1.06 & $0.76-1.46$ \\
3 & 56 & 91 & 1.25 & $0.85-1.84$ \\
$\geq 4$ & 26 & 45 & 1.14 & $0.66-1.94$ \\
Previous intrauterine death & & & & \\
0 & 264 & 515 & 1.0 & Reference \\
1 & 5 & 9 & 1.08 & $0.28-3.64$ \\
\hline Total & 269 & 524 &. &. \\
\hline
\end{tabular}

As the cases and referents in the medical records study were matched for maternal age, the analysis of maternal age as a putative risk factor was made comparing cases with all infants born in the region, stratifying for year of birth and parity. Paternal age is not available in the register and was therefore analyzed in the medical records study. This analysis studied paternal age independent of its covariation with maternal age.

This study was approved by the local ethics committee.

\section{Results}

\section{Maternal and paternal age}

Table 2 gives the odds ratios for maternal and paternal age. No clear-cut maternal age dependency was found even though a nonsignificant $\mathrm{U}$-form was indicated. There was no trend for paternal age, but the age group of 30-34 years had a lower than expected odds ratio, which reached statistical significance.

Most of the following results were based on the medical records study, but they were supplemented with register data when stated.

\section{Reproductive history}

Table 3 summarizes the data on reproductive history. The results indicate an excess of women with involuntary childlessness among the cases in comparison with the referents. When this factor was studied in the register study, a similar result was obtained. The odds ratio for having 1-5 years of involuntary childlessness was 1.24 (95\% CI 0.99-1.42), and for 5 years or more it was 1.40 (95\% CI 0.97-2.05). The odds ratio for any reported period of infertility was 1.28 (95\% CI 1.07-1.53).

The results indicate an excess of spontaneous abortions among the cases when they were compared with the referents, although the result did not reach statistical significance.

None of the parity groups showed a significant difference between the cases and referents, and the tendency towards an increase in the odds ratio with parity was not statistically significant $(\mathrm{z}=1.71, \mathrm{P}=0.09)$.

\section{Maternal illness and drug use}

The only maternal disease associated with an increased risk for congenital heart malformation was maternal diabetes mellitus (OR 1.96, 95\% CI 0.36-10.6, based on 4 cases and 4 referents). When this factor was studied using the register data, the finding was similar (OR 2.38, 
95\% CI 1.36-4.15). Urine tract infection, epilepsy, asthma, inflammatory bowel disease, systemic lupus erythematosus, conception hypertension, and thyroid disease occurred equally among the cases and referents.

Table 4 lists reported drug use in early pregnancy. The numbers were low, but an excess risk was found for drugs used for thyroid disease and nonsteroid antiinflammatory drugs among the cases. The three women using antiepileptic drugs all had infants with a cardiac defect, and the odds ratio was formally statistically significant. There was no significant total excess of drug use among the cases when they were compared with referents.

Oral contraceptive use in early pregnancy was identified from the medical records (ie, date of stopping its use in relation to the date of last menstrual period). It was not associated with congenital heart defect in the infant (7 of 269 in the case group, 13 of 524 in the reference group, OR 1.05, 95 \% CI 0.35-2.87).

\section{Maternal smoking and alcohol use}

Information on maternal smoking and alcohol use in early pregnancy is shown in table 5 .

There was a slight excess of maternal smoking among the cases, but it did not reach statistical significance. No effect of reported alcohol use was found.

\section{Maternal body mass index}

BMI could be calculated for 231 cases and 446 referents. The distribution is shown in table 6 , which contains data from both the medical records study and the register study. In the medical records study, there was a U-shaped relationship with the lowest odds ratio for normal BMI values (19.8-25.9). A similar trend was found when the BMI was calculated from the register data.

\section{Parental occupation}

Detailed information on occupational exposure was not available, but broad parental occupational categories were given. No differences between the cases and referents could be identified for any maternal or paternal occupational category.

\section{Discussion}

Most studies on the importance of nongenetic factors in the etiology of cardiac defects are based on retrospective interview data or questionnaires, sometimes long after the birth of the infant. This method of data collection may carry the risk for recall bias, and, when interviews are part of routine birth defect registration, interviewer bias can also be involved. This
Table 4. Reported drug use in early pregnancy and the risk of congenital heart defect in the offspring. (NSAID = nonsteroid antiinflammatory drugs)

\begin{tabular}{lrrrc}
\hline Drug category & $\begin{array}{c}\text { Cases } \\
(\mathrm{N})\end{array}$ & $\begin{array}{c}\text { Referents } \\
(\mathrm{N})\end{array}$ & OR & $95 \% \mathrm{Cl}$ \\
\hline Drugs for hyperacidity & 1 & 2 & 0.97 & $0.02-18.8$ \\
Beta-blocking drugs & 1 & 7 & 0.28 & $0.01-2.17$ \\
Drugs for thyroid disease & 3 & 2 & 2.94 & $0.33-35.4$ \\
Antibiotics & 11 & 16 & 1.35 & $0.56-3.16$ \\
NSAID & 5 & 4 & 2.46 & $0.52-12.5$ \\
Muscle relaxants & 1 & 3 & 0.65 & $0.01-8.11$ \\
Analgesics & 6 & 20 & 0.57 & $0.19-1.51$ \\
Antiepileptic drugs & 3 & - & $\infty$ & $1.14-\infty$ \\
Sedatives & 2 & 3 & 1.30 & $0.11-11.4$ \\
Beta-stimulating drugs & 5 & 10 & 0.97 & $0.26-3.16$ \\
Inhaled corticosteroids & 2 & 6 & 0.65 & $0.06-3.65$ \\
Any drug except vitamins & 63 & 106 & 1.21 & $0.83-1.76$ \\
\hline Total & 269 & 524 &. &. \\
\hline
\end{tabular}

Table 5. Reported maternal smoking and alcohol use in early pregnancy and the risk of a congenital heart defect in the infant. The odds ratios (OR) were calculated from a case-referent comparison in the medical records study. $(95 \% \mathrm{Cl}=95 \%$ confidence interval)

\begin{tabular}{lcccc}
\hline & $\begin{array}{c}\text { Cases } \\
(\mathrm{N})\end{array}$ & $\begin{array}{c}\text { Referents } \\
(\mathrm{N})\end{array}$ & OR & $95 \% \mathrm{Cl}$ \\
\cline { 2 - 5 } & & & & \\
Smoking & 5 & 9 &. &. \\
$\quad$ Not stated & 186 & 381 & 1.0 & Reference \\
$\quad$ None & 53 & 84 & 1.29 & $0.86-1.93$ \\
$\quad<10$ cigarettes/day & 25 & 50 & 1.02 & $0.59-1.75$ \\
$\geq 10$ cigarettes/day & 78 & 134 & 1.19 & $0.84-1.68$ \\
$\quad$ Any smoking & & & & \\
Alcohol & 13 & 32 &. &. \\
$\quad$ Not stated & 142 & 267 & 1.0 & Reference \\
$\quad$ None & 114 & 225 & 0.95 & $0.69-1.31$ \\
$\quad$ Alcohol use & 269 & 524 &. &. \\
\hline Total & & & & \\
\hline
\end{tabular}

Table 6. Association between maternal body mass index (BMI) and the risk of congenital heart defect in the infant. ${ }^{a}(\mathrm{R}=0 \mathrm{dds}$ ratio, $95 \% \mathrm{Cl}=95 \%$ confidence interval)

\begin{tabular}{|c|c|c|c|c|c|c|}
\hline \multirow[t]{2}{*}{ BMI } & \multicolumn{4}{|c|}{ Medical records study } & \multicolumn{2}{|c|}{ Register study } \\
\hline & $\begin{array}{l}\text { Cases } \\
\text { (N) }\end{array}$ & $\begin{array}{l}\text { Referents } \\
\text { (N) }\end{array}$ & $\mathrm{OR}$ & $95 \% \mathrm{Cl}$ & $\mathrm{OR}$ & $95 \% \mathrm{Cl}$ \\
\hline $\begin{array}{r}<19.8 \\
19.8-25.9 \\
26-28.9 \\
\geq 29\end{array}$ & $\begin{array}{r}50 \\
139 \\
19 \\
23\end{array}$ & $\begin{array}{r}75 \\
305 \\
36 \\
30\end{array}$ & $\begin{array}{l}1.37 \\
0.70 \\
1.02 \\
1.53\end{array}$ & $\begin{array}{l}0.90-2.07 \\
0.50-0.99 \\
0.54-1.88 \\
0.83-2.81\end{array}$ & $\begin{array}{l}1.09 \\
0.83 \\
0.96 \\
1.46\end{array}$ & $\begin{array}{l}0.82-1.45 \\
0.68-1.00 \\
0.72-1.28 \\
1.12-1.90\end{array}$ \\
\hline Total & 231 & 446 & . & . & & . \\
\hline
\end{tabular}

a The adjusted odds ratios in the register study were estimated with the Mantel-Haenszel procedure after stratification for year of birth, maternal age, parity, and smoking.

phenomenon has been much discussed in the literature with arguments both for and against the existence of recall bias (11). 
The existence of a medical birth register with information recorded in early pregnancy and therefore prospective as regards the identification of congenital malformation makes it possible to perform large-scale studies. An example is the recent study on the association between maternal smoking in early pregnancy and congenital heart defects (5). The advantage of such register studies is the large number of persons, which gives high statistical power and makes it possible to demonstrate weak effects. The drawback is that only factors recorded in the register can be studied, and the validity of the information (although nonbiased) may be far from perfect.

We tried therefore to increase and validate the available information by adding data from medical records. This process necessitated a case-referent approach and limitation of the study to a region where access to the medical records was comparatively easy. In order to get a reasonable number of cases, only infants with a relatively severe cardiac defect were used as cases. As the definition, we used conditions that were identified from reports obtained from the child cardiology center, and these reports also guaranteed correct and definitive diagnoses.

For some specific questions, when exposure data were available in the register, all cardiovascular defects (except for PDA and SUA) were used as cases, and all infants born were used as referents (ie, the register study). In this way the statistical power increases, but imperfect exposure data, as well as less certain cardiac defect data, bias the risk estimates towards unity. An example is the association of cardiac defects with involuntary childlessness. In the medical records study, an odds ratio of 1.33 was found, but statistical significance was not reached. In the register study, a slightly lower odds ratio was found that reached statistical significance.

For other risk factors, an increased odds ratio may have appeared in the medical records study without reaching statistical significance. If data had been available (and trustworthy) in the register, perhaps the increase could have been supported or rejected. One example is the increased odds ratio for previous spontaneous abortion (12) and the U-formed relationship between maternal age and the risk for cardiac defect (4).

The absence of demonstrable effects may have different explanations. A true association may have been missed because of a lack of statistical power due to low numbers (notably for the study based on medical records) or because of low validity in exposure information (eg, occupational exposure where only maternal and paternal occupation was known).

The data presented in this paper refer to the prevalence of a congenital heart defect at birth. Such data may not reflect the true incidence if prenatal selection of malformed embryos or fetuses occurs through spontaneous or selectively induced abortions. The impact of induced abortion after the prenatal identification of a heart defect is negligible in Sweden if fetuses with chromosome anomalies are excluded (which was the case in the present study). A risk factor that causes a selective loss of embryos or fetuses with a cardiac defect may not be detectable in a study based on infants born. In our study we tried to identify risk factors for cardiac defects in fetuses that survived to birth, which is the group representing the practically important problem.

We could verify some known risk factors for cardiac defects [eg, maternal diabetes mellitus (13) and use of antiepileptic drugs (14)]. Other postulated risk factors could not be verified. Alcohol abuse is known to be teratogenic, and among the effects seen are cardiac defects (15). We saw no association between reported maternal use of alcohol and cardiac defects. This finding may be due to the low validity of the exposure information, which did not differentiate regular users from temporary users. The prevalence of alcoholism among pregnant women in Sweden is relatively low. Our data refer to light or moderate alcohol use, which does not seem to be harmful.

Paternal age has been suggested as a risk factor for cardiac defects, notably ventricular septal defect, atrial septal defect, and PDA (16). We found no certain paternal age effect in our material, and this result agrees with findings in an earlier Swedish study (17). The previously suggested (18) association between the use of oral contraceptives in early pregnancy and cardiac defects could not be verified.

Use of medical drugs seems not to be a major factor in the etiology of congenital cardiac defects according to our data, with the exception of antiepileptic drugs. It is, however, possible that an association exists with the use of nonsteroid anti-inflammatory drugs although statistical significance was not reached in this study. A recent paper supports this observation (19). The indicated excess risk with drugs used for thyroid disease should be further explored in a larger material.

We found another possible risk factor that has previously not been extensively discussed in relation to congenital cardiovascular malformation, namely, high BMI. Obesity is associated with an increased risk for neural tube defects (20), and it seems possible that a similar association is found with cardiac defects (21). Hypothetically, an explanation could be undetected diabetes type 2 , which may be associated with an increased risk for congenital heart disease $(22,23)$.

We found no new strong risk factor of importance for an individual pregnant woman but, from the population point of view, weak risk factors could also be of interest. There is an increasing frequency of pregnant women with a high BMI in the Swedish population. The 
association between a high BMI and congenital heart defects may therefore be of importance from a public health perspective.

\section{Acknowledgments}

The Östergötland County Council supported this study. We thank the National Board of Health and Social Welfare, Stockholm, for access to its health registers.

\section{References}

1. Bruyere HJ Jr, Kargas SA, Levy JM. The causes and underlying developmental mechanism of congenital cardiovascular malformations: a critical review. Am J Med Genet Suppl 1987;3:411-31.

2. Ferencz C, Loffredo CA, Correa-Villaseñor A, Wilson PD. Genetic and environmental risk factors of major cardiovascular malformations, the Baltimore-Washington infant study 1981-1989. Perspect Pediatr Cardiol 1997; 5:359-82.

3. Tikkanen J, Heinonen OP. Risk factors for cardiovascular malformations in Finland. Eur J Epidemiol 1990;6:348-56.

4. Pradat P. Epidemiology of major congenital heart defects in Sweden, 1981-1986. J Epidemiol Community Health 1992; 46:211-5.

5. Källén K. Maternal smoking and congenital heart defects. Eur J Epidemiol 1999;15:731-7.

6. Blomberg M, Selbing A, Källén B. Congenital malformations in the southeast region of Sweden: a registry study with validation. Acta Paediatr 2000;89:1238-43.

7. Carlgren LE, Ericsson A, Källén B. Monitoring of congenital cardiac defects. Pediatr Cardiol 1987;8:247-56.

8. Cnattingius S, Ericsson A, Gunnarskog J, Källén B. A quality study of a medical birth registry. Scand J Soc Med 1990;18:143-8.

9. Mantel N, Haenszel W. Statistical aspects of the analyses of data from retrospective studies of disease. J Natl Cancer Inst
1959;22:719-48.

10. Miettinen OS. Simple interval estimation of risk ratio. Am J Epidemiol 1974;100:515-6.

11. Källén B. Human studies - epidemiologic techniques in developmental toxicology. In: Hood RD. editor. Handbook of developmental toxicology. Boca Raton (FL): CRC Press, 1997: 597-631.

12. Sheiner E, Katz M, Fraser D, Gohar J, Carmi R. The relationship between congenital cardiovascular malformations and spontaneous abortion in preceding pregnancy. Paediatr Perinat Epidemiol 1998;12:128-35.

13. Rowland TW, Hubbell JP, Nadas AS. Congenital heart disease in infants of diabetic mothers. J Pediatr 83;5:815-20.

14. Bossi L. Fetal effects of anticonvulsants. In: Morselli PL, Pippenger CE, Penry JK, editors. Antiepileptic drug therapy in pediatrics. New York (NY): Raven Press, 1983:37-64.

15. Alpert JJ, Zuckerman B. Alcohol use during pregnancy: what is the risk? Pediatr Rev 1991;12:375-9.

16. Olshan AF, Schnitzer PG, Baird PA. Paternal age and risk of congenital heart defects. Teratology 1994;50:80-4.

17. Pradat P. Effect of fathers' age and birth order on occurrence of congenital heart defects. J Epidemiol Community Health 1992;46:460

18. Heinonen OP, Slone D, Monson RR, Hook EB, Shapiro S. Cardiovascular birth defects and antenatal exposure to female sex hormones. N Engl J Med 1977;296:67-70.

19. Ericson A. Källén BAJ. Nonsteroidal anti-inflammatory drugs in early pregnancy. Reprod Toxicol 2001;15:371-5.

20. Källén K. Maternal smoking, body mass index, and neural tube defects. Am J Epidemiol 1998;147:1103-11.

21. Watkins ML, Botto LD. Maternal prepregnancy weight and congenital heart defects in offspring. Epidemiology 2001; 12: 439-46.

22. Towner D, Kjos SL, Leung B, Montoro MM, Xiang A, Mestman JH, et al. Congenital malformations in pregnancies complicated by NIDDM. Diabetes Care 1995;18:1446-51.

23. Åberg A, Westbom L, Källén B. Congenital malformations among infants whose mothers had gestational diabetes or preexisting diabetes. Early Hum Dev 2001;61:85-95.

Received for publication: 17 April 2001 